\title{
Apple as a Source of Dietary Phytonutrients: Bioavailability and Evidence of Protective Effects against Human Cardiovascular Disease
}

\author{
Gianna Ferretti ${ }^{*}$, Imma Turco ${ }^{1}$, Tiziana Bacchetti ${ }^{2}$ \\ ${ }^{1}$ Dipartimento di Scienze Cliniche Sperimentali e Odontostomatologiche, Università Politecnica delle Marche, \\ Ancona, Italia \\ 2Dipartimento di Scienze Della Vita e dell'Ambiente, Università Politecnica delle Marche, Ancona, Italia \\ Email: ${ }^{*}$ g.ferretti@univpm.it
}

Received 19 April 2014; revised 20 May 2014; accepted 4 June 2014

Copyright $@ 2014$ by authors and Scientific Research Publishing Inc.

This work is licensed under the Creative Commons Attribution International License (CC BY).

http://creativecommons.org/licenses/by/4.0/

(c) () Open Access

\section{Abstract}

The dietary consumption of fruit and vegetable is associated with a lower incidence of degenerative diseases such as cardiovascular disease. Most recent interest has focused on the bioactive phenolic compounds in vegetable products. All varieties of apple contain several antioxidants and polyphenols that possess many biological activities, such as antioxidant and anti-inflammation properties. The review describes the nutritional properties of apples and their derivatives, with a particular attention to polyphenol compounds. Moreover, the health benefits of apples and the potential molecular mechanisms against cardiovascular disease are reviewed.

Keywords

Antioxidants, Apples, Cardiovascular Disease, Phytocompounds, Polyphenols

\section{Introduction}

Several studies have demonstrated that fruits and vegetables exert a protective effect against the development of human diseases such as cardiovascular disease, diabetes and cancer [1]-[4]. It has been hypothesized that the protective role could be due to nutrients contained in the vegetables such as fiber, vitamins and phytochemicals. Among phytochemicals, the protective role of phenolics has been mainly investigated. Phenolics are secondary

*Corresponding author.

How to cite this paper: Ferretti, G., Turco, I. and Bacchetti, T. (2014) Apple as a Source of Dietary Phytonutrients: Bioavailability and Evidence of Protective Effects against Human Cardiovascular Disease. Food and Nutrition Sciences, 5, $1234-1246$. http://dx.doi.org/10.4236/fns.2014.513134 
plant metabolites characterized by having at least one aromatic ring with one or more hydroxyl groups attached. The nature and the distribution of phenolics differ by plant tissue, with many of the phenolics synthesized from carbohydrates via the shikimate and phenyl propanoid pathways. Phenolics range from simple, low molecular weight, single-aromatic ring compounds to the large complex tannins. Polyphenols generally occur as glycosylated derivatives in plants, although conjugation with inorganic acid and malonylation is also known [5] [6].

Apples are among the most widely consumed fruits in various countries. They are widely consumed fresh or in processed forms, such as juices and dried apple. Apples contain several nutrient as well as non-nutrient components, including dietary fiber, minerals, and vitamins (Table 1). Moreover, apple is one of the main natural sources of phytochemicals most of which express relevant antioxidant capacities in vitro [7]-[9]. The biological activities of apple polyphenols have often been evaluated in vitro on cultured cells and in animal models [7] [10] [11]. Previous studies have also investigated the effect of apples derivatives. Among these, apple pomace, a waste material from apple juice processing, which contains significant amounts of dietary fiber and phytochemicals has been studied [12] [13]. However, it has to be stressed that it is not always clear whether the effects in animals can be extrapolated to humans. Furthermore, studies in cell culture have been conducted before it is known that phytochemicals are processed in vivo, how they are absorbed and metabolized in the body. For

Table 1. Average nutrient content in apple (per $100 \mathrm{~g}$ fresh weight) (Jensen et al. 2009).

\begin{tabular}{|c|c|}
\hline Constituents & Contents \\
\hline Water (g) & 85.3 \\
\hline Energy $(\mathrm{Kcal} / \mathrm{kJ})$ & $54 / 227$ \\
\hline Protein (g) & 0.3 \\
\hline Fat (g) & 0.6 \\
\hline Carbohydrates (g) & 12.9 \\
\hline Fructose & 5.7 \\
\hline Glucose & 0.6 \\
\hline Sucrose & 0.57 \\
\hline Fiber (g) & 2.7 \\
\hline Insoluble & 0.7 \\
\hline Soluble & 2 \\
\hline Pectin (g) & 0.5 \\
\hline Potassium (mg) & 144 \\
\hline Calcium (mg) & 7.0 \\
\hline Magnesium (mg) & 6.0 \\
\hline Phosphorus (mg) & 12.0 \\
\hline Thiamin (mg) & 0.016 \\
\hline Riboflavin (mg) & 0.011 \\
\hline Vitamin B6 (mg) & 0.051 \\
\hline Folate (mg) & 9 \\
\hline Vitamin C (mg) & 12 \\
\hline Organic fruit acids (g) & 0.5 \\
\hline Total polyphenols (mg) & 111.45 \\
\hline Flavanols (mg) & 96.33 \\
\hline Flavonols (mg) & 5.66 \\
\hline Dihydrochalcones (mg) & 4.18 \\
\hline Anthocyanins (mg) & $1.62^{\mathrm{a}}$ \\
\hline Hydroxycinnamic acids (mg) & 14.21 \\
\hline
\end{tabular}

a. in red apples. 
example, some phytochemicals are fermented by colonic bacteria and the original phytochemical may not even be detectable in the blood [14].

This review focuses on the nutrient and phytochemical contents of apples. An overview on the bioavailability and metabolism of the most abundant apple phytochemicals after consumption is also presented, and the currently hypothesized health benefits related to apple consumption in humans are reviewed, with a particular attention given to recent evidence on the impact of apple on cardiovascular health and the biological effects related to the protective effect of this fruit.

\section{Apples Nutritional Properties and Phytochemicals}

The chemical composition and the nutritional properties of different cultivar of apple and their derivatives (juice, dried apple) have been previously studied [15] [16]. According to its nutrient profile (Table 1), apple represents a healthy food choice.

\subsection{Sugars}

Ninety-percent of the energy from apples is derived from simple carbohydrates, mainly sugars, of which fructose is the dominant form. Apple fructose and sucrose contents are lower than in most other fruits.

The fibre content of apple is approx. $3 \mathrm{~g} / 100 \mathrm{~g}$ fresh weight (FW) and consists mainly of soluble fibres (pectin) (Table 1). Pectin is a complex polysaccharide, and apple pectin exhibits a high degree of esterification and a particularly high content of branched side chains [17]. Pectin exerts different physiological roles. It exerts prebiotic effects [18] and is fermented by the microflora in the large intestine resulting in the formation of short chain fatty acids (SCFA) which are absorbed and metabolised in the colonic mucosa, liver, or peripheral tissues. It has been established a relationship between the consumption of pectins and maintenance of normal blood cholesterol concentrations and a reduction of post-prandial glycaemic responses [19].

\subsection{Micronutrients}

Apple also contains several nutrient as well as non-nutrient components, including, minerals, and vitamins. Apples are rich in vitamins $\mathrm{C}$ and $\mathrm{E}$, some pro-vitamin A carotenes, lutein, folic acid, potassium and magnesium (Table 1).

\subsection{Phytochemicals}

Some of the most well studied polyphenol compounds in apples include flavonoids such as quercetin-3-galactoside, quercetin-3-glucoside, quercetin-3-rhamnoside [7] [15]. Lister et al. [20] reported quercetin glycoside concentrations of $400-700 \mathrm{mg} / 100 \mathrm{~g}$ and $250-550 \mathrm{mg} / 100 \mathrm{~g}$ in Granny Smith and Splendour apple peels, respectively, with quercetin 3-galactoside (hyperin), quercetin 3-arabinofuranoside (avicularin), quercetin 3rhamnoside (quercetin), and quercetin 3-xyloside (reynoutrin) being the four most common. Apples contain also flavanols ([+]catechin [-]epicatechin). Other phytochemicals are antocyanins (cyanidin-3-galactoside), coumaric acid, chlorogenic acid, gallic acid, and certain dihydrochalcones only found in apples (phloridzin and phloretin) [21]. Schieber et al., [22] have demonstrated the presence of isorhamnetin glycosides in extracts of "Brettacher" apples that are used both as a dessert fruit and for juice. The flavanols of apples are very similar to those present in cocoa and dark chocolate, and apples represent potential sources of extractable flavanols for inclusion in functional foods. The apple contains also condensed tannins. The apple condensed tannins (ACT) are contained in unripe apples at a ten times higher level than in the ripe ones [23]. Condensed tannins are called proanthocyanidins (PA). PA differ from all other natural polyphenols by their polymeric nature. They are made of flavan-3-ol units and their average degree of polymerization generally varies between 3 and 11 [24]. Polymerization degree may reach values as high as 17 as was shown in an apple cider extract by Guyot et al. [25]. We consume small amounts of these compounds in daily life from fresh fruits such as apple and the processed foods made from these fruits.

Previous studies have also evaluated the concentration of phytochemicals between the apple peels and the apple flesh. Apple peels contain from two to six times (depending on the variety) more phenolic compounds than in the flesh, and two to three times more flavonoids in the peels when compared to the flesh. The antioxidant activity of apple peels is much greater, ranging from two to six times greater in the peels when compared to the 
flesh, depending on the variety of the apple [7]-[9]. Quercetin conjugates are found exclusively in the peel of the apples. Chlorogenic acid tends to be higher in the flesh than in the peel. In agreement with the polyphenol composition, apples with the peels are better able to inhibit cancer cell proliferation when compared to apples without the peels [26].

\section{Bioavailability of Apple Phytochemicals in Humans}

Bioavailability is defined as the proportion of a phytochemical that is digested, absorbed, and utilized in normal metabolism; however, measurement of bioavailability relies heavily upon estimates of amounts of antioxidant absorbed. Positive health effects of apple-derived polyphenols in vivo depend on their absorption, metabolism, distribution, and elimination from the body after consumption. Prerequisites for these compounds to have any in vivo effects are that they must be absorbed from the gastrointestinal tract after food consumption and subsequently reach sufficiently high plasma concentrations in the systemic circulation to induce biological activity. Bioavailability of polyphenols may be influenced by food matrix and dose ingested. A major part of the polyphenols ingested (75\% - 99\%) is not found in urine. This implies they have either not been absorbed through the gut barrier, absorbed and excreted in the bile or metabolized by the colonic microflora or our own tissues. Only very rare measurements of the intestinal absorption of polyphenols in humans are available [14] [27] [28]. Large uncertainties remain due to the lack of comprehensive data on the content of some of the main polyphenol classes in food. The maximum concentration in plasma rarely exceeds 1 microM after the consumption of 10 $100 \mathrm{mg}$ of a single phenolic compound. However, the total plasma phenol concentration is probably higher due to the presence of metabolites formed in the body's tissues or by the colonic microflora. The bioavailability of some apple phytonutrients has been recently investigated in human studies and the results are summarized.

Dihydrochalcones. Phloretin (Phl) has been found exclusively in apples and in apple-derived products where is present as free and its glucosidic form, phloridzin (phloretin 2'-O-glucose). The bioavailability of dihydrochalcones following the consumption of apples and apple cider has been investigated in ileostomists and healthy subjects [29] [30]. After ingestion, the principal component in apples and cider, phloretin glucosides undergo cleavage in the small intestine with the released phloretin being subject to glucuronidation before appearing rapidly in the circulatory system as plorethin-2-O-glucuronide with a Tmax lower than $1 \mathrm{~h}$. The short duration of the $T_{\max }$ values and the similar $\mathrm{C}_{\max }$ of the glucuronide in healthy subjects and in ileostomist subjects after apple cider intake are indicative of absorption in the prossimal gastrointestinal tract. Glucuronide derivative has been detected in ileal fluid, urine, and plasma samples in addition to minor amounts of Phl conjugates (glucuronides and sulfates) and unconjugated Phl in the ileal samples [29] [30].

Epicatechin. The bioavailability of the flavanol epicatechin has been studied using an apple extract (apple drink) and an apple puree containing different amounts of epicatechin (70 $\mathrm{mg}$ and $140 \mathrm{mg}$ ) [31]. The results of the randomized, placebo-controlled, crossover trial demonstrated that maximum plasma concentration, absorption and urinary excretion were all significantly higher after ingestion of both epicatechin drinks compared with apple puree ( $<$ 0.05). Epicatechin bioavailability was $>2$-fold higher after ingestion of the $140 \mathrm{mg}$ epicatechin drink compared to the $70 \mathrm{mg}$ epicatechin drink ( $<0.05$ ). The authors concluded that oral bioavailability of apple epicatechin increased at higher doses, but was reduced by whole apple matrix when compared with a epicatechin-rich apple extract incorporated in water-based drink [31].

Quercetin. As far as it concerns the bioavailability of apple quercetin, previous studies have demonstrated that is lower when compared with onions [32]. DuPont et al. [33] have also determined the uptake and excretion of low doses of polyphenols in six subjects who each consumed $1.1 \mathrm{~L}$ of an alcoholic cider beverage. No quercetin was found in urine or plasma, but 3'-methyl quercetin was detected in plasma suggesting that low doses of quercetin are extensively methylated in humans [28] [33].

Condensed tannin bioavailability. Very little is known about the metabolic fate and bioavailability of tannins. Proanthocyanidins (PA) absorption depends on their degree of polymerization [34]. In some in vitro experiments, only PA dimers and trimers, but not polymers with an average polymerization degree of 7, were absorbed through an intestinal epithelium cell monolayer [35]. Déprez et al. [36] have demonstrated that in vitro PA are catabolized by human colonic microflora into low-molecular-weight phenolic acids.

Other apple polyphenols. Two human intervention studies have investigated the bioavailability of other apple polyphenols in healthy men after ingestion of apples from different farming systems. The short-term intervention study included six men who consumed either organically or conventionally produced apples (randomized 
cross-over study). After intake of $1 \mathrm{~kg}$ apples, phloretin and coumaric acid plasma concentrations increased significantly ( $\mathrm{p}<0.0001)$ in both intervention groups, without differences between the two farming systems. In the long-term intervention study, 43 healthy volunteers consumed organically or conventionally produced apples ( $500 \mathrm{~g} /$ day; 4 weeks) or no apples in a double-blind, randomized intervention study. In the study, $24 \mathrm{~h}$ after the last dosing regime, the apple intake did not result in increasing polyphenol concentrations in plasma and urine compared to the control group suggesting no accumulation of apple polyphenols or degradation products in humans [37].

\section{Apples and Risk of Cardiovascular Disease. Human Studies}

Apple consumption, including fresh apple, apple juice, apple extracts, apple polyphenols or apple pectin have been reported to exert cardioprotective effects in various animal models [7] [11] [38]-[41]. Most of these studies have concluded that the health benefits of apple consumption may be related to any of its components, including fiber and phytochemicals. However, findings from these studies cannot be directly extrapolated to human beings. Evidence from human epidemiologic and interventional studies is growing. Even if it is difficult to demonstrate that specific foods can play a part in decreasing cardiovascular disease (CVD) and heart disease, some epidemiologic observations have suggested that apples may have particular beneficial cardiovascular effects. Alterations of plasma lipoproteins, endothelial dysfunction and increased production of proinflammatory molecules are involved in the molecular mechanisms of cardiovascular disease [42] [43]. Evidence suggests that consumption of apple or its bioactive components modulate lipid metabolism and reduce the production of proinflammatory molecules. As summarized by Boyer and Liu [7], some reports showed an inverse association between apple derivatives and apple-flavonoid intake and coronary mortality. Gender-related differences have been observed, in fact a $43 \%$ reduction in coronary mortality group has been demonstrated in women consuming $>71 \mathrm{~g}$ of apple/d compared to women who did not eat apples. In men, the risk reduction was only $19 \%$ in the group consuming >54 g compared to no apple intake [44]. Other studies have shown that a relatively modest intake of apple is associated with modifications of plasma lipids and a protective effect against lipid peroxidation.

\subsection{Lipids and Lipid Metabolism}

Elevated lipids and aberrations in plasma lipoproteins are well-established risk factors for cardiovascular disease [42] [43] [45]. Research in animals allows for detailed analyses of the effect of apple derivatives on lipid parameters beyond simply measuring lipid levels in plasma. The effect of apples on plasma cholesterol levels and cardiovascular risk has been reviewed in 2009 [38]. More recent studies have confirmed that apple and derivatives exert an effect on plasma lipids in human subjects (Table 2).

Chai et al. [46] have studied the effect of ingestion of dried apple (75 g/day) in one-hundred sixty postmenopausal women compared with a control group whose diet was supplemented with dried plum (comparative control) [46]. Fasting blood samples were collected at baseline, 3, 6, and 12 months to measure various parameters. Women who consumed dried apple lost $1.5 \mathrm{~kg}$ body weight by the end of the study. In terms of cholesterol, serum total cholesterol levels were significantly lower in the dried apple group compared with the dried plum group only at 6 months. Within the group, women who consumed dried apple had significantly lower serum levels of total cholesterol and low-density lipoprotein (LDL) cholesterol by $9 \%$ and $16 \%$, respectively, at 3

Table 2. Human studies. Apples and their effect on plasma lipids.

\begin{tabular}{|c|c|c|c|}
\hline \multirow{2}{*}{ Apple or derivate } & \multicolumn{3}{|c|}{ Treatments } \\
\hline & Time & Results & References \\
\hline Dried apple (75 g) & 3 - 12 months & Decreased total cholesterol and LDL-C & Chai et al., 2012 \\
\hline $\begin{array}{l}\text { Fresh apples ( } 550 \mathrm{mg} \text { ) or processed apple products } \\
\text { ( } 500 \mathrm{ml} \text { clear, juice, cloudy juice and air-dried } \\
\text { pomace } 22 \mathrm{~g} / \text { day) }\end{array}$ & 28 days & $\begin{array}{l}\text { Decreased LDL-C (fresh apples group) } \\
\text { Increased LDL-C (clear juice group) }\end{array}$ & Ravn-Haren et al., 2013 \\
\hline 300 g raw Golden delicious apple/day & 8 weeks & No effect & Hyson et al., 2000 \\
\hline Apple juice (750 ml)/day & 4 weeks & No effect & Barth et al. 2012 \\
\hline Apple polyphenols (600 mg/day) & 12 weeks & Decreased total cholesterol & Nagasako et al., 2007 \\
\hline
\end{tabular}


months compared with baseline. These serum values were further decreased to $13 \%$ and $24 \%$, respectively, after 6 months but stayed constant thereafter. The within-group analysis also reported that daily apple consumption profoundly improved atherogenic risk ratios.

A crossover study to assess the effects of whole apples (550 g/day), apple pomace ( $22 \mathrm{~g} /$ day), clear and cloudy apple juices (500 ml/day) or no supplement on lipoproteins and blood pressure in a group of 34 healthy volunteers confirmed a significant effect on serum total and LDL-cholesterol [47]. Trends towards a lower serum LDL-concentration were observed after whole apple (6.7\%), pomace (7.9\%) and cloudy juice (2.2\%) intake. On the other hand, LDL-cholesterol (LDL-C) concentrations increased by $6.9 \%$ with clear juice compared to whole apples and pomace. There was no effect on HDL-cholesterol, triacylglicerol (TAG), composition of the gut microbiota or markers of glucose metabolism. It was concluded that the fibre component was necessary for the cholesterol-lowering effect of apples in healthy humans and that clear apple juice may not be a suitable surrogate for the whole fruit in nutritional recommendations. In addition to fibre, the effect on plasma lipids could be due to apple polyphenols, in fact although only a small fraction of these is absorbed, two studies have reported a cholesterol-lowering effect after 4 weeks supplementation with an apple polyphenol extract [48].

In contrast with the aforementioned papers, a study on hyperlipidemic and overweight men whose diet was supplemented with 300 g complete raw Golden Delicious apple daily for 8 weeks did not confirm an effect on plasma lipids [49]. Moreover, a recent study by Barth et al. (2012) has demonstrated no significant effect of moderate intake of apple juice on plasma lipids in obese men. However a decrease in the percent body fat in obese patients was demonstrated [50].

\subsection{Endothelial Function and Blood Pressure}

Nitric oxide (NO), which can be derived from both endogenous and exogenous sources, is a critical regulator of endothelial function [51]. Dietary components, such as particular flavonoids can augment NO status acutely and in so doing enhance endothelial function. Flavonoids increase endogenous endothelial NO production and/or reduce breakdown [52]. These effects may contribute to the benefits of flavonoid-rich foods and beverages on cardiovascular health [53]. The acute effects of apples, rich in flavonoids (providing $184 \mathrm{mg}$ of quercetin and $180 \mathrm{mg}$ of (-)-epicatechin.), on plasma NO status, endothelial function, and blood pressure has been studied by Bondonno et al. [54] in healthy men and women in a randomized, controlled, crossover trial. Measurements included plasma nitric oxide status, assessed by measuring S-nitrosothiols, other nitrosylated species (RXNO) and nitrite, blood pressure, and endothelial function, measured as flow-mediated dilatation of the brachial artery. Relative to control, all treatments resulted in higher RXNO. Compared to control, the treatment resulted in higher flow-mediated dilatation (FMD) $(\mathrm{p}<0.05)$ and lower pulse pressure $(\mathrm{p}<0.05)$. No significant effect was observed on diastolic blood pressure. Therefore the authors concluded that intake of flavonoid-rich apples can augment nitric oxide status, enhance endothelial function, and lower blood pressure acutely, outcomes that may benefit cardiovascular health [55].

In disagreement with the previous studies, Auclair et al. [55] demonstrated that consumption of a polyphenol-rich apple does not improve vascular function studied by brachial artery FMD in 30 hypercholesterolemic patients who had consumed $40 \mathrm{~g}$ of two lyophilized apples, polyphenol-rich and polyphenol-poor, providing respectively 1.43 and $0.21 \mathrm{~g}$ polyphenol per day.

\subsection{Inflammatory Markers}

Antiinflammatory properties of apple polyphenols have previously investigated in vitro [34] [56]. Elevated serum levels of C-reactive protein (CRP) have been implicated in many chronic diseases, including CVD. Another health benefit of apple may be through its ability to lower CRP levels. More recently, CRP has been identified as a major contributor and predictor of the development of atherosclerosis, CVD complications, and diabetes [57]. Chai et al. demonstrated a decrease of serum CRP levels by 22\% in a group of women supplemented with dried apple for 6 months and the level of serum CRP further decreased by 32\% after 12 months [46].

\subsection{Oxidative Stress}

Overproduction and/or overexposure to oxidants in the body can result in an imbalance leading to cellular damage. Oxidative damage appears to be an initiating factor in several chronic diseases, including cardiovascular 
disease, due to disruptions in DNA, protein, lipids, and other cellular components by reactive oxygen species (ROS) [58]. Dietary antioxidants are of interest, because they add to the endogenous potential of the body to scavenge ROS and nitrogen-free radicals and directly counteract lipid peroxidation reactions [59] [60].

The antioxidant activity of apples has been widely investigated in vitro using different experimental models. Several studies have reported that the antioxidant activity differs between different varieties of apples and is positively associated with the level of phenolic content: the apple varieties with the higher phenolics tended to have higher antioxidant activity "in vitro" [7] [61].

Wolfe et al. [62] have reported that of four common varieties used for apple sauce (Rome Beauty, Idared, Cortland, and Golden Delicious), Rome Beauty had the highest phenolic content and the highest antioxidant properties. Out of 10 varieties commonly consumed in the US, Fuji and Red Delicious apples had the highest phenolic compounds and highest antioxidant properties [7]. On the contrary, Zardo et al. [63] reported that Golden Delicious had the highest phenol content compared to Fuji and Gala and the antioxidant capacity of the Golden Delicious was 2.5 and 3.6 times higher than that found in the Fuji and Gala, respectively. The phenolic composition of 67 varieties of apple cultivars (new and old varieties) was examined for the concentration of some important phytochemicals and antioxidant activity by Wojdyło et al (2008) [64]. The results confirms the correlation between levels of polyphenols and "in vitro" antioxidant properties [64].

Also tannins could be involved in the antioxidant properties of apples. In fact, plant proanthocyanidins possess a variety of physiological activities including antioxidant activity [65]-[67] and are known as the functional food factors [34]. Recent researches have shown that the degree of polymerization of these substances is related to their antioxidant activity. In condensed tannins, this activity can be up to fifteen to thirty times superior to those attributed to simple phenols [68].

The antioxidant properties of apples have also been investigated in humans. The results are summarized in Table 3.

Post prandial changes of blood antioxidants. Using a fluorescent probe (2,7-dichlorofluorescin) as an indicator of ROS formation and oxidative stress, it has been demonstrated that intake of $150 \mathrm{~mL}$ of apple juice prepared from homogenized apple flesh [59] was associated with a significant increase of antioxidant effect within 30 min post-consumption that was sustained for up to $90 \mathrm{~min}$.

Maffei et al. [69] have confirmed that apple intake (600 g) of homogenized unpeeled apples, Red Delicious) in a small group of young healthy males $(n=6)$, increased plasma total antioxidant activity by $64 \%$ at 3 and $6 \mathrm{~h}$ post-consumption compared to a water control, with resumption to baseline by $24 \mathrm{~h}$ after the test. Apple also decreased the presence of ROS generated by hydrogen peroxide exposure in lymphocytes isolated from each participant at 3 and $6 \mathrm{~h}$ after the apple test meal. The investigators tested also for the ability of apple to protect against DNA damage in cultured lymphocytes isolated after apple exposure and found a significant protective

Table 3. Human studies. Apples and their effect on oxidative stress.

\begin{tabular}{|c|c|c|c|}
\hline \multirow{2}{*}{ Apple or derivate } & \multicolumn{3}{|c|}{ Treatments } \\
\hline & Time & Results & References \\
\hline $\begin{array}{l}\text { Apple (apple fresh plus skin) } \\
=184 \mathrm{mg} \text { of quercetin and } \\
180 \mathrm{mg} \text { of (-)-epicatechin }\end{array}$ & $\begin{array}{l}10 \text { months } \\
\text { (breakfast and lunch) }\end{array}$ & Higher RXNO levels & Bondonno et al., 2012 \\
\hline $\begin{array}{l}375 \mathrm{ml} \text { of unsupplemented } \\
\text { apple juice or } 340 \mathrm{~g} \text { of } \\
\text { cored whole apple }\end{array}$ & $\begin{array}{l}6 \text { weeks, then crossed } \\
\text { over to the alternate } \\
\text { product for } 6 \text { weeks }\end{array}$ & $\begin{array}{l}\text { Increased ex vivo copper } \\
\mathrm{Cu}(++) \text {-mediated LDL oxidation lag time. } \\
\text { Decreased conjugated diene formation. } \\
\text { Increased antioxidant activity. }\end{array}$ & Hyson et al., 2000 \\
\hline Dried apple (75 g) & 3 - 12 months & Decreased levels of plasma lipid peroxides & Chai et al., 2012 \\
\hline Fresh apples (2 g/kg) & 30 days & Increase in erythrocyte SOD and GPx & Avci et al., 2007 \\
\hline One apple a day & 30 days & Decrease of oxLDL- $\beta 2 \mathrm{GPI}$ & Zhao et al., 2013 \\
\hline Apple homogenate (600 g) & & $\begin{array}{l}\text { Post prandial increase of plasma total } \\
\text { antioxidant activity } \\
\text { Protective effect against lipid peroxidation }\end{array}$ & Maffei et al., 2007 \\
\hline Apple juice (300 ml) & & $\begin{array}{l}\text { Decrease of lipid peroxidation of lymphocytes } \\
\text { Post prandial decrease in serum lipid peroxides }\end{array}$ & Vieira et al., 2012 \\
\hline
\end{tabular}


effect at $3 \mathrm{~h}$ with a gradual loss of protection $24 \mathrm{~h}$ post-consumption. These findings suggest that the consumption of whole apple provides a useful dietary source of active scavengers to protect cells and tissue from oxidative stress and related DNA injury. A protective effect exerted by apple intake on lymphocyte DNA has been observed by Brivida et al. [70].

Vieira et al. [71] confirmed that acute consumption of apple juice (AJ) of 2 Brazilian cultivars (Golden Delicious and Catarina) with different content of sugars, ascorbic acid, phenols, and antioxidant capacities exert an effect on the antioxidant status and serum lipid peroxidation (lipid hydroperoxides and thiobarbituric acid-reactive substances, TBARS) in humans. The study carried out in nine healthy women who ingested $300 \mathrm{~mL}$ of Golden Delicious or Catarina apple juice or water, demonstrated a significant increase in serum antioxidant capacity and ascorbic and uric acid levels and a significant decrease in serum lipid peroxidation 1 hour after intake. The increase in serum antioxidant capacity after consumption of both AJ was correlated directly with the uric acid levels and inversely with serum lipid peroxidation. The acute intake of AJ of 2 cultivars promoted a similar effect on the antioxidant status and lipid peroxidation in human blood serum.

Other authors have suggested that the increase of plasma antioxidant capacity after apple intake (Red Delicious) [71], is mainly due to the enhancement of uric acid in serum whereas polyphenols and ascorbic acid play a negligible role. In fact it has been demonstrated that the fructose in apples caused the increase in uric acid levels because of the increased degradation of adenosine monophosphate to uric acid [72].

Long term effects. Modification of antioxidant activity in the participants' erythrocytes and plasma has been demonstrated after intake of fresh apples at a daily dose of $2 \mathrm{~g} / \mathrm{kg}$ for 1 month [73]. The study carried out in 15 elderly participants (mean age 72 years) demonstrated that apple consumption increased antioxidant potential in plasma and cell antioxidant enzymes, including superoxide dismutase (SOD) and glutathione peroxidase (GPx) in erythrocytes. The up regulation of these enzymes suggested that regular apple consumption might promote a favorable milieu to reduce oxidation. More recently Chai et al. [46] demonstrated that intake of dried apple (75 g/day) for 12 months was able to decrease levels of serum lipid hydroperoxides.

Lipid peroxidation of lipoproteins. In the past few years, research on polyphenols as antioxidants has considerably increased because of the involvement of oxidative stress in the onset and development of degenerative disease [58] [60]. The effect of phytochemicals on in vitro low-density lipoprotein (LDL) oxidation has been previously studied. In fact, the oxidative modification hypothesis designates the oxidative change of LDL as a crucial, if not mandatory, step in atherogenesis [43] [74]. This theory originated from studies demonstrating that LDL modified by endothelial cells, transformation entailing an oxidation process [75], could be internalized and accumulated avidly by macrophages [76]. Reports of in vivo antioxidant effects from fruit intake are limited. A human trial examined the in vivo effect of consumption of apples (both whole and juice) in an unblinded, randomized, crossover design. Healthy men and women added $375 \mathrm{ml}$ of unsupplemented apple juice or $340 \mathrm{~g}$ of cored whole apple (Cripps Pink apple) to their daily diet for 6 weeks, then crossed over to the alternate product for 6 weeks. Dietary fiber intake increased by $22 \%$ with whole apple consumption. Moderate apple juice consumption provided in vivo antioxidant activity as shown by the increased ex vivo copper $(\mathrm{Cu}(++))$-mediated LDL oxidation lag time by $20 \%$ in subjects whose diet had been supplement with apple juice. Moreover apples and apple juice both reduced conjugated diene formation. In view of the understanding of CVD, the observed effect on LDL might be associated with reduced CVD risk and supports the inclusion of apple juice in a healthy human diet [49].

Phenolics that bind LDL are good candidates for preventing lipid peroxidation and atherosclerotic processes because they are able to prevent the autocatalytic chain reaction of fatty acid peroxidation in LDL directly and/or by preservation of other chain-breaking antioxidants, such as tocopherol [77].

A recent study has also investigated the effect of apple intake ( 1 apple/day for 4 weeks, an equal mixture of Red Delicious and Golden Delicious apples) on levels of oxidized low-density lipoprotein/ $\beta 2$-glycoprotein I (oxLDL- $\beta 2$ GPI) complex [78]. The complex oxLDL- $\beta 2$ GPI is thought to initiate a process that leads to atherosclerosis [79]. The results have demonstrated that the consumption of one apple per day caused a substantial decrease in the parameter (mean value of $40 \%$ ) [78] [79].

\section{Conclusions}

In vitro apple polyphenols have been identified as potent radical scavenger, antioxidant and anti-inflammatory molecules. The effect of different varieties of apple has been recently investigated in human epidemiologic and 
Table 4. Potential disease-preventive mechanisms of apple and their active constituents as identified in human dietary studies.

\begin{tabular}{cc}
\hline Potential disease-preventive mechanisms & Key active components \\
\hline Antioxidant activity (ROS and RNS) & Flavonoids, Ascorbic acid, Pronthocyanidins \\
Blood pressure reduction & Flavonoids \\
Modifications of plasma lipids and lipoprotein levels & Fibres (Pectin), Polyphenols \\
Modulation of endothelial cells & Flavonoids \\
Anti-inflammatory properties & Flavonoids, Proanthocyanidins \\
\hline
\end{tabular}

interventional studies. The results demonstrate that the consumption of the fresh and dried apple exerts a beneficial effect to human health. Different molecular mechanisms, as summarized in Table 4, can be suggested to explain the protective effect exerted by apple components.

The beneficial effects of whole apples on plasma lipid levels are probably related to synergistic interactions between apple components. Contrasting results have been reported in obese and hypercholesterolemic patients. Additional human studies are needed to confirm the hypothesized antioxidant, antinflammatory, and vascular protective effects of apples and derivatives in normal and pathological conditions.

\section{References}

[1] Hu, F.B. (2003) Plant-Based Foods and Prevention of Cardiovascular Disease: An Overview. The American Journal of Clinical Nutrition, 8, 544S-551S.

[2] He, F., Nowson, C.A., Lucas, M. and MacGregor, G.A. (2007) Increased Consumption of Fruit and Vegetables Is Related to a Reduced Risk of Coronary Heart Disease: Meta-Analysis of Cohort Studies. Journal of Human Hypertension, 21, 717-728. http://dx.doi.org/10.1038/sj.jhh.1002212

[3] Riboli, E. and Norat T. (2003) Epidemiologic Evidence of the Protective Effect of Fruit and Vegetables on Cancer Risk. The American Journal of Clinical Nutrition, 78, 559S-569S.

[4] Steinmetz, K.A. and Potter, J.D. (1996) Vegetables, Fruit, and Cancer Prevention: A Review. Journal of the American Dietetic Association, 96, 1027-1039. http://dx.doi.org/10.1016/S0002-8223(96)00273-8

[5] Scalbert, A. and Williamson, C. (2000) Dietary Intake and Bioavailability of Polyphenols. Journal of Nutrition, 130, 2073S-2085S.

[6] Monach, C., Scalbert, A., Morand, C., Remesy, C. and Jimenez, L. (2004) Polyphenols: Food Sources and Bioavailability. The American Journal of Clinical Nutrition, 79, 727-747.

[7] Boyer, J. and Liu, RH. (2004) Apple Phytochemicals and Their Health Benefits. Nutrition Journal, 12, 3-5.

[8] Wolfe, K., Wu, X. and Liu, R.H. (2003) Antioxidant Activity of Apple Peels. Journal of Agricultural and Food Chemistry, 51, 609-614. http://dx.doi.org/10.1021/jf020782a

[9] Eberhardt, M., Lee, C. and Liu, R.H. (2000) Antioxidant Activity of Fresh Apples. Nature, 405, 903-904.

[10] Miura, D., Miura, Y. and Yagasaki, K. (2007) Effect of Apple Polyphenol Extract on Hepatoma Proliferation and Invasion in Culture and on Tumor Growth, Metastasis, and Abnormal Lipoprotein Profiles in Hepatoma-Bearing Rats. Bioscience, Biotechnology, and Biochemistry, 71, 2743-2750. http://dx.doi.org/10.1271/bbb.70359

[11] Osada, K., Suzuki, T. and Kawakami, Y. (2006) Dose-Dependent Hypocholesterolemic Actions of Dietary Apple Polyphenol in Rats Fed Cholesterol. Lipids, 41, 133-139. http://dx.doi.org/10.1007/s11745-006-5081-y

[12] Kosmala, M., Kołodziejczyk, K., Zduńczyk, Z., Juśkiewicz, J. and Boros, D. (2011) Chemical Composition of Natural and Polyphenol-Free Apple Pomace and the Effect of This Dietary Ingredient on Intestinal Fermentation and Serum Lipid Parameters in Rats. Journal of Agricultural and Food Chemistry, 14, 9177-9185. http://dx.doi.org/10.1021/jf201950y

[13] Yan, H. and Kerr, W.L. (2013) Total Phenolics Content, Anthocyanins, and Dietary Fiber Content of Apple Pomace Powders Produced by Vacuum-Belt Drying. Journal of the Science of Food and Agriculture, 93, 1499-1504. http://dx.doi.org/10.1002/jsfa.5925

[14] Del Rio, D., Rodriguez-Mateos, A., Spencer, J.P., Tognolini, M., Borges, G. and Crozier A. (2013) Dietary (Poly) Phenolics in Human Health: Structures, Bioavailability, and Evidence of Protective Effects against Chronic Diseases. Antioxidants Redox Signaling, 18, 1818-1892. http://dx.doi.org/10.1089/ars.2012.4581 
[15] Podsedek, A., Wilska-Jeska, J., Anders, B. and Markowski, J. (2000) Compositional Characterisation of Some Apple Varieties. European Food Research and Technology, 210, 268-272. http://dx.doi.org/10.1007/s002179900101

[16] Kahle, K., Kraus, M. and Richling, E. (2005) Polyphenol Profiles of Apple Juices. Molecular Nutrition \& Food Research, 49, 797-806. http://dx.doi.org/10.1002/mnfr.200500064

[17] Thakur, B.R., Singh, R.K., Handa, A.K. and Rao, M.A. (1997) Chemistry and Uses of Pectin-A Review. Critical Reviews in Food Science and Nutrition, 37, 47-73. http://dx.doi.org/10.1080/10408399709527767

[18] Olano-Martin, E., Gibson, G.R. and Rastell, R.A. (2002) Comparison of the in Vitro Bifidogenic Properties of Pectins and Pectic-Oligosaccharides. Journal of Applied Microbiology, 93, 505-511. http://dx.doi.org/10.1046/j.1365-2672.2002.01719.x

[19] EFSA Panel on Dietetic Products, Nutrition and Allergies (NDA). EFSA Journal, 8, 1747-1745.

[20] Lister, C.E., Lancaster, J.E., Sutton, K.H. and Walker, J.R.L. (1994) Developmental Changes in the Concentration and Composition of Flavonoids in Skin of a Red and a Green Apple Cultivar. Journal of the Science of Food and Agriculture, 64, 155-161. http://dx.doi.org/10.1002/jsfa.2740640204

[21] Escarpa, A. and Gonzales, M.C. (1998) High Performance Liquid Chromatography with Diode-Array Detection for the Determination of Phenolic Compounds in Peel and Pulp from Different Apple Varieties. Journal of Chromatography A, 823, 331-337. http://dx.doi.org/10.1016/S0021-9673(98)00294-5

[22] Schieber, A., Keller, P., Streker, P., Klaiber, I. and Carle, R. (2001) Detection of Isorhamnetin Glycosides in Extracts of Apples (Malus domestica cv. "Brettacher") by HPLC-PDA and HPLC-APCIMS/MS. Phytochemical Analysis, 13, 87-94..

[23] Lea, A.G.H. and Arnold, G.M. (1978) The Phenolics of Ciders: Bitterness and Astringency. Journal of the Science of Food and Agriculture, 29, 478-483. http://dx.doi.org/10.1002/jsfa.2740290512

[24] Santos-Buelga, C. and Scalbert, A. (2000) Proanthocyanidins and Tannin-Like Compounds-Nature, Occurrence, Dietary Intake and Effects on Nutrition and Health. Journal of the Science of Food and Agriculture, 80, 1094-1117. http://dx.doi.org/10.1002/(SICI)1097-0010(20000515)80:7<1094::AID-JSFA569>3.0.CO;2-1

[25] Guyot, S., Marnet, N., Laraba, D., Sanoner, P. and Drilleau, J.F. (1998) Reversed-Phase HPLC Following Thiolysis for Quantitative Estimation and Characterization of the Four Main Classes of Phenolic Compounds in Different Tissue Zones of a French Cider Apple Variety. Journal of Agricultural and Food Chemistry, 46, 1698-1705. http://dx.doi.org/10.1021/jf970832p

[26] Denis, M.C., Furtos, A., Dudonné, S., Montoudis, A., Garofalo, C., Desjardins, Y., Delvin, E. and Levy, E. (2013) Apple Peel Polyphenols and Their Beneficial Actions on Oxidative Stress and Inflammation. PLoS ONE, 8, Article ID: e53725. http://dx.doi.org/10.1371/journal.pone.0053725

[27] Landete, J.M. (2012) Updated Knowledge about Polyphenols: Functions, Bioavailability, Metabolism, and Health. Critical Reviews in Food Science and Nutrition, 52, 936-948. http://dx.doi.org/10.1080/10408398.2010.513779

[28] Bergmann, H., Triebel, S., Kahle, K. and Richling, E. (2010) The Metabolic Fate of Apple Polyphenols in Humans. Current Nutrition \& Food Science, 6, 19-35. http://dx.doi.org/10.2174/157340110790909554

[29] Richling, E. (2012) Bioavailability of Dihydrochalcones. In: Spencer, J.P.E. and Crozier, A., Eds., Flavonoids and Related Compounds: Bioavailability and Function, CRC Press, Boca Raton, 157-165.

[30] Marks, C., Mullen, W., Borges, G. and Crozier, A. (2009) Absorption, Metabolism, and Excretion of Cider Dihydrochalcones in Healthy Humans and Subjects with an Ileostomy. Journal of Agricultural and Food Chemistry, 57, 2009-2015. http://dx.doi.org/10.1021/jf802757x

[31] Hollands, W.J., Hart, D.J., Dainty, J.R., Hasselwander, O., Tiihonen, K., Wood, R. and Kroon, P.A. (2013) Bioavailability of Epicatechin and Effects on Nitric Oxide Metabolites of an Apple Flavanol-Rich Extract Supplemented Beverage Compared to a Whole Apple Puree: A Randomized, Placebo-Controlled, Crossover Trial. Molecular Nutrition \& Food Research, 57, 1209-1217. http://dx.doi.org/10.1002/mnfr.201200663

[32] Hollman, P.C., van Trijp, J.M., Buysman, M.N., van der Gaag, M.S., Mengelers, M.J., de Vries, J.H. and Katan, M.B. (1997) Relative Bioavailability of the Antioxidant Flavonoid Quercetin from Various Foods in Man. FEBS Letters, 418, 152-156. http://dx.doi.org/10.1016/S0014-5793(97)01367-7

[33] Du Pont, M.S., Bennett, R.N., Mellon, F.A. and Williamson, G. (2002) Polyphenols from Alcoholic Apple Cider Are Adsorbed, Metabolized and Excreted by Humans. Journal of Nutrition, 132, 172-175.

[34] Serrano, J., Puupponen-Pimiä, R., Dauer, A., Aura, A.M. and Saura-Calixto, F. (2009) Tannins: Current Knowledge of Food Sources, Intake, Bioavailability and Biological Effects. Molecular Nutrition \& Food Research, 53, S310-S329. http://dx.doi.org/10.1002/mnfr.200900039

[35] Déprez, S., Mila, I. and Scalbert, A. (1999) Carbon-14 Biolabeling of (+)-Catechin and Proanthocyanidin Oligomers in Willow Tree Cuttings. Journal of Agricultural and Food Chemistry, 47, 4219-4230. 
http://dx.doi.org/10.1021/jf981380z

[36] Déprez, S., Brezillon, C., Rabot, S., Philippe, C., Mila, I., Lapierre, C. and Scalbert, A. (2000) Polymeric Proanthocyanidins Are Catabolized by Human Colonic Microflora into Low-Molecular-Weight Phenolic Acids. Journal of Nutrition, 130, 2733-2738.

[37] Stracke, B.A., Rüfer, C.E., Bub, A., Seifert, S., Weibel, F.P., Kunz, C. and Watzl, B. (2010) No Effect of the Farming System (Organic/Conventional) on the Bioavailability of Apple (Malus domestica Bork., Cultivar Golden Delicious) Polyphenols in Healthy Men: A Comparative Study. European Journal of Nutrition, 49, 301-310. http://dx.doi.org/10.1007/s00394-009-0088-9

[38] Jensen, E.N., Buch-Andersen, T., Ravn-Haren, G. and Dragsted, L. (2009) Mini-Review: The Effects of Apples on Plasma Cholesterol Levels and Cardiovascular Risk-A Review of the Evidence. Journal of Horticultural Science \& Biotechnology, 34-41.

[39] Auclair, S., Silberberg, M., Gueux, E., Morand, C., Mazur, A., Milenkovic, D. and Scalbert, A. (2008) Apple Polyphenols and Fibers Attenuate Atherosclerosis in Apolipoprotein E-Deficient Mice. Journal of Agricultural and Food Chemistry, 56, 5558-5563. http://dx.doi.org/10.1021/jf800419s

[40] Hyson, D.A. (2011) A Comprehensive Review of Apples and Apple Components and Their Relationship to Human Health. Advances in Nutrition, 2, 408-420. http://dx.doi.org/10.3945/an.111.000513

[41] Toh, J.Y., Tan, V.M., Lim, P.C., Lim, S.T. and Chong, M.F. (2013) Flavonoids from Fruit and Vegetables: A Focus on Cardiovascular Risk Factors. Current Atherosclerosis Reports, 15, 368. http://dx.doi.org/10.1007/s11883-013-0368-y

[42] Eren, E., Yilmaz, N. and Aydin, O. (2013) Functionally Defective High-Density Lipoprotein and Paraoxonase: A Couple for Endothelial Dysfunction in Atherosclerosis. Cholesterol, 2013, Article ID: 792090. http://dx.doi.org/10.1155/2013/792090

[43] Maiolino, G., Rossitto, G., Caielli, P., Bisogni, V., Rossi, G.P. and Calò, L.A. (2013) The Role of Oxidized Low-Density Lipoproteins in Atherosclerosis: The Myths and the Facts. Mediators of Inflammation, 2013, Article ID: 714653. http://dx.doi.org/10.1155/2013/714653

[44] Knekt, P., Jarvinen, R., Reunanen, A. and Maatela, J. (1996) Flavonoid Intake and Coronary Mortality in Finland: A Cohort Study. British Medical Journal, 312, 478-481. http://dx.doi.org/10.1136/bmj.312.7029.478

[45] Assmann, G. and Schulte, H. (1988) The Prospective Cardiovascular Münster (PROCAM) Study: Prevalence of Hyperlipidemia in Persons with Hypertension and/or Diabetes Mellitus and the Relationship to Coronary Heart Disease. American Heart Journal, 116, 1713-1724. http://dx.doi.org/10.1016/0002-8703(88)90220-7

[46] Chai, S.C., Hooshmand, S., Saadat, R.L., Payton, M.E., Brummel-Smith, K. and Arjmandi, B.H. (2012) Daily Apple versus Dried Plum: Impact on Cardiovascular Disease Risk Factors in Postmenopausal Women. Journal of the Academy of Nutrition and Dietetics, 112, 1158-1168. http://dx.doi.org/10.1016/j.jand.2012.05.005

[47] Ravn-Haren, G., Dragsted, L.O., Buch-Andersen, T., Jensen, E.N., Jensen, R.I., Németh-Balogh, M., Paulovicsová, B., Bergström, A., Wilcks, A., Licht, T.R., Markowski, J. and Bügel, S. (2013) Intake of Whole Apples or Clear Apple Juice Has Contrasting Effects on Plasma Lipids in Healthy Volunteers. European Journal of Nutrition, 52, 1875-1889. http://dx.doi.org/10.1007/s00394-012-0489-Z

[48] Nagasako-Akazome, Y., Kanda, T., Ohtake, Y., Shimasaki, H. and Kobayashi, T. (2007) Apple Polyphenols Influence Cholesterol Metabolism in Healthy Subjects with Relatively High Body Mass Index. Journal of Oleo Science, 56, $417-$ 428. http://dx.doi.org/10.5650/jos.56.417

[49] Hyson, D., Studebaker-Hallman, D., Davis, P.A. and Gershwin, M.E. (2000) Apple Juice Consumption Reduces Plasma Low-Density Lipoprotein Oxidation in Healthy Men and Women. Journal of Medicinal Food, 3, 159-166. http://dx.doi.org/10.1089/jmf.2000.3.159

[50] Barth, S.W., Koch, T.C., Watzl, B., Dietrich, H., Will, F. and Bub, A. (2012) Moderate Effects of Apple Juice Consumption on Obesity-Related Markers in Obese Men: Impact of Diet-Gene Interaction on Body Fat Content. European Journal of Nutrition, 51, 841-850. http://dx.doi.org/10.1007/s00394-011-0264-6

[51] Lorin, J., Zeller, M., Guilland, J.C., Cottin, Y., Vergely, C. and Rochette, L. (2014) Arginine and Nitric Oxide Synthase: Regulatory Mechanisms and Cardiovascular Aspects. Molecular Nutrition \& Food Research, 58, 101-116. http://dx.doi.org/10.1002/mnfr.201300033

[52] Loke, W.M., Hodgson, J.M., Proudfoot, J.M., McKinley, A.J., Puddey, I.B. and Croft, K.D. (2008) Pure Dietary Flavonoids Quercetin and (-)-epicatechin Augment Nitric Oxide Products and Reduce Endothelin-1 Acutely in Healthy Men. American Journal of Clinical Nutrition, 88, 1018-1025.

[53] Galleano, M., Pechanova, O. and Fraga, C.G. (2010) Hypertension, Nitric Oxide, Oxidants, and Dietary Plant Polyphenols. Current Pharmaceutical Biotechnology, 11, 837-848. http://dx.doi.org/10.2174/138920110793262114

[54] Bondonno, C.P., Yang, X., Croft, K.D., Considine, M.J., Ward, N.C., Rich, L., Puddey, I.B., Swinny, E., Mubarak, A. and Hodgson, J.M. (2012) Flavonoid-Rich Apples and Nitrate-Rich Spinach Augment Nitric Oxide Status and Improve 
Endothelial Function in Healthy Men and Women: A Randomized Controlled Trial. Free Radical Biology and Medicine, 52, 95-102. http://dx.doi.org/10.1016/j.freeradbiomed.2011.09.028

[55] Auclair, S., Chironi, G., Milenkovic, D., Hollman, P.C., Renard, C.M., Mégnien, J.L., Gariepy, J., Paul, J.L., Simon, A. and Scalbert, A. (2010) The Regular Consumption of a Polyphenol-Rich Apple Does Not Influence Endothelial Function: A Randomised Double-Blind Trial in Hypercholesterolemic Adults. European Journal of Clinical Nutrition, 64, 1158-1165. http://dx.doi.org/10.1038/ejen.2010.135

[56] Andre, C.M., Greenwood, J.M., Walker, E.G., Rassam, M., Sullivan, M., Evers, D., Perry, N.B. and Laing, W.A. (2012) Anti-Inflammatory Procyanidins and Triterpenes in 109 Apple Varieties. Journal of Agricultural and Food Chemistry, 60, 10546-10554. http://dx.doi.org/10.1021/jf302809k

[57] González-Jiménez, E., Montero-Alonso, M.A. and Schmidt-Ríovalle, J. (2013) C-Reactive Protein as a Biochemical Marker of Cardiovascular Risk. Nutrición Hospitalaria, 28, 2182-2187.

[58] Chen, Y.R. and Zweier, J.L. (2014) Cardiac Mitochondria and Reactive Oxygen Species Generation. Circulation Research, 114, 524-537. http://dx.doi.org/10.1161/CIRCRESAHA.114.300559

[59] Ko, S.H., Choi, S.W., Ye, S.K., Cho, B.L., Kim, H.S. and Chung, M.H. (2005) Comparison of the Antioxidant Activities of Nine Different Fruits in Human Plasma. Journal of Medicinal Food, 8, 41-46. http://dx.doi.org/10.1089/jmf.2005.8.41

[60] Machlin, J. and Bendich, A. (1987) Free Radical Tissue Damage: Protective Role of Antioxidant Nutrients. FASEB Journal, 1, 441-445.

[61] Carbone, K., Giannini, B., Picchi, V., Lo Scalzo, R. and Cecchini, F. (2011) Phenolic Composition and Free Radical Scavenging Activity of Different Apple Varieties in Relation to the Cultivar, Tissue Type and Storage. Food Chemistry, 127, 493-500. http://dx.doi.org/10.1016/j.foodchem.2011.01.030

[62] Wolfe, K., Wu, X.Z. and Liu, R.H. (2003) Antioxidant Activity of Apple Peels. Journal of Agricultural and Food Chemistry, 51, 609-614. http://dx.doi.org/10.1021/jf020782a

[63] Zardo, D.M., Silva, K.M., Guyot, S. and Nogueira, A. (2013) Phenolic Profile and Antioxidant Capacity of the Principal Apples Produced in Brazil. International Journal of Food Sciences and Nutrition, 64, 611-620. http://dx.doi.org/10.3109/09637486.2013.763909

[64] Wojdyło, A., Oszmiański, J. and Laskowski, P. (2008) Polyphenolic Compounds and Antioxidant Activity of New and Old Apple Varieties. Journal of Agricultural and Food Chemistry, 56, 6520-6530. http://dx.doi.org/10.1021/jf800510j

[65] Lea, A.G.H. and Tinberlake, C.F. (1974) The Phenolics of Ciders: 1. Procyanidins. Journal of the Science of Food and Agriculture, 25, 1537-1545. http://dx.doi.org/10.1002/jsfa.2740251215

[66] Goupy, P., Amiot, M.J., Richard-Forget, F., Duprat, F., Aubert, S. and Nicolas, J. (1995) Enzymatic Browning of Model Solutions and Apple Phenolic Extracts by Apple Polyphenol Oxidase. Journal of Food Science, 60, 497-501. http://dx.doi.org/10.1111/j.1365-2621.1995.tb09811.x

[67] Burda, S., Oleszek, W. and Lee, C.Y. (1990) Phenolic Compounds and Their Changes in Apples during Maturation and Cold Storage. Journal of Agricultural and Food Chemistry, 38, 945-948. http://dx.doi.org/10.1021/jf00094a006

[68] Sánchez-Moreno, C. (2002) Compuestos polifenólicos: Efectos fisiológicos: Actividad antioxidante. Alimentaria, 329, 29-40.

[69] Maffei, F., Tarozzi, A., Carbone, F., Marchesi, A., Hrelia, S., Angeloni, C., Forti, G. and Hrelia, P. (2007) Relevance of Apple Consumption for Protection against Oxidative Damage Induced by Hydrogen Peroxide in Human Lymphocytes. British Journal of Nutrition, 97, 921-927. http://dx.doi.org/10.1017/S0007114507665192

[70] Briviba, K., Stracke, B.A., Rufer, C.E., Watzl, B., Weibel, F.P. and Bub, A. (2007) Effect of Consumption of Organically and Conventionally Produced Apples on Antioxidant Activity and DNA Damage in Humans. Journal of Agricultural and Food Chemistry, 55, 7716-7721. http://dx.doi.org/10.1021/jf0710534

[71] Vieira, F.G., Di Pietro, P.F., da Silva, E.L., Borges, G.S., Nunes, E.C. and Fett, R. (2012) Improvement of Serum Antioxidant Status in Humans after the Acute Intake of Apple Juices. Nutrition Research, 32, 229-232. http://dx.doi.org/10.1016/j.nutres.2011.12.008

[72] Lotito, S.B. and Frei, B. (2004) The Increase in Human Plasma Antioxidant Capacity after Apple Consumption Is Due to the Metabolic Effect of Fructose on Urate, Not Apple-Derived Antioxidant Flavonoids. Free Radical Biology and Medicine, 37, 251-258. http://dx.doi.org/10.1016/j.freeradbiomed.2004.04.019

[73] Avci, A., Atli, T., Eruder, I., Varli, M., Devrim,E., Turgay, S. and Durak, I. (2007) Effect of Apple Consumption on Plasma and Erythrocyte Antioxidant Parameters in Elderly Subjects. Experimental Aging Research, 33, 429-437. http://dx.doi.org/10.1080/03610730701525352

[74] Steinberg, D., Parthasarathy, S., Carew, T.E., Khoo, J.C. and Witztum, J.L. (1989) Beyond Cholesterols Modifications of Low-Density Lipoprotein that Increase Its Atherogenicity. New England Journal of Medicine, 320, 915-924. 
[75] Steinbrecher, U.P., Parthasarathy, S., Leake, D.S., Witztum, J.L. and Steinberg, D. (1984) Modification of Low Density Lipoprotein by Endothelial Cells Involves Lipid Peroxidation and Degradation of Low Density Lipoprotein Phospholipids. Proceedings of the National Academy of Sciences of the United States of America, 81, 3883-3887. http://dx.doi.org/10.1073/pnas.81.12.3883

[76] Henriksen, T., Mahoney, E.M. and Steinberg, D. (1983) Enhanced Macrophage Degradation of Biologically Modified Low Density Lipoprotein. Arteriosclerosis, Thrombosis, and Vascular Biology, 3, 149-159. http://dx.doi.org/10.1161/01.ATV.3.2.149

[77] Zhu, Q.Y., Huang, Y. and Chen, Z.Y. (2000) Interaction between Flavonoids and $\alpha$-Tocopherol in Human Low Density Lipoprotein. Journal of Nutritional Biochemistry, 11, 14-21. http://dx.doi.org/10.1016/S0955-2863(99)00065-0

[78] Zhao, S., Bomser, J., Joseph, E.L. and Di Silvestro, R.A. (2013) Intakes of Apples or Apple Polyphenols Decrease Plasma Values for Oxidized Low-Density Lipoprotein/B2-Glycoprotein I Complex. Journal of Functional Foods, 5, 493-497. http://dx.doi.org/10.1016/j.jff.2012.08.010

[79] Matsuura, E., Kobayashi, K., Inoue, K., Lopez, L. and Shoenfeld, Y. (2005) Oxidized LDL/ß2-Glycoprotein I Complexes: New Aspects in Atherosclerosis. Lupus, 14, 736-741. http://dx.doi.org/10.1191/0961203305lu22110a

\section{Abbreviations}

ACT, apple condensed tannins;

AJ, apple juice;

CRP, C-reactive protein;

CVD, cardiovascular disease;

FMD, flow-mediated dilatation;

FW, fresh weight;

GPX, glutathione peroxidase;

$\mathrm{NO}$, nitric oxide;

RXNO, nitrosylated species;

Phl, phloretin;

LDL, low-density lipoprotein;

LDL-C, LDL-cholesterol;

PA, proanthocyanidins;

ROS, reactive oxygen species;

SCFA, short chain fatty acids;

SOD, superoxide dismutase;

TAG, triacylglicerol;

TBARS, thiobarbituric acid-reactive substances;

oxLDL/ $\beta 2$ GPI, oxidized low-density lipoprotein/ $\beta 2$-glycoprotein I complex. 
Scientific Research Publishing (SCIRP) is one of the largest Open Access journal publishers. It is currently publishing more than 200 open access, online, peer-reviewed journals covering a wide range of academic disciplines. SCIRP serves the worldwide academic communities and contributes to the progress and application of science with its publication.

Other selected journals from SCIRP are listed as below. Submit your manuscript to us via either submit@scirp.org or Online Submission Portal.
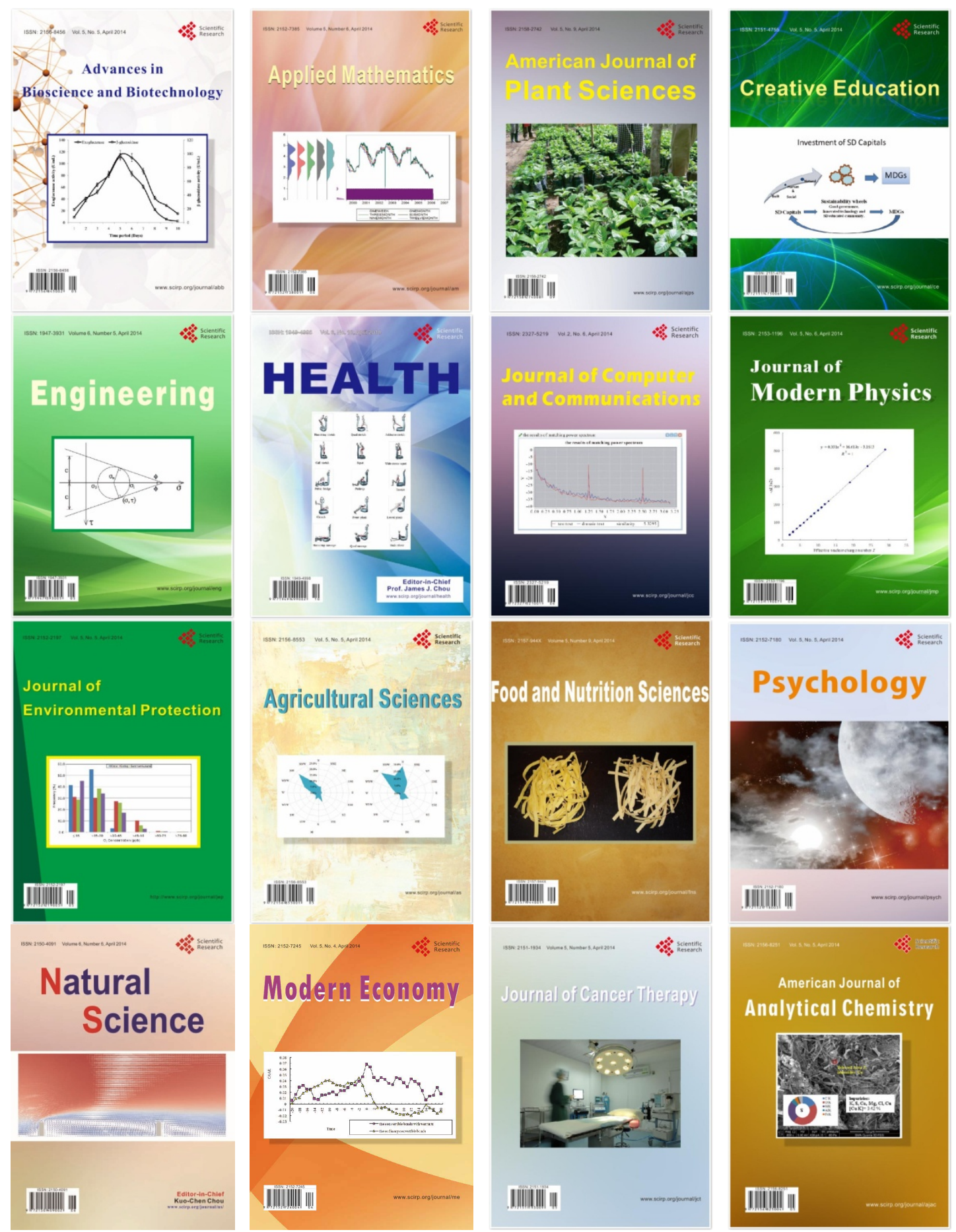